\title{
CatB is Critical for Total Catalase Activity and Reduces Bactericidal Effects of Phenazine-1-Carboxylic Acid on Xanthomonas oryzae pv. oryzae and $X$. oryzae pv. oryzicola
}

\author{
Xiayan Pan, Jian Wu, Shu Xu, Yabing Duan, and Mingguo Zhou
}

College of Plant Protection, State \& Local Joint Engineering Research Center of Green Pesticide Invention and Application, Nanjing Agricultural University, Nanjing, 210095, China.

Accepted for publication 9 October 2016.

\begin{abstract}
Rice bacterial leaf blight, caused by Xanthomonas oryzae pv. oryzae, and rice bacterial leaf streak, caused by X. oryzae pv. oryzicola, are major diseases of rice. Phenazine-1-carboxylic acid (PCA) is a natural product that is isolated from Pseudomonas spp. and is used to control many important rice diseases in China. We previously reported that PCA disturbs the redox balance, which results in the accumulation of reactive oxygen species in $X$. oryzae pv. oryzae. In this study, we found that PCA significantly upregulated the transcript levels of catB and katE, which encode catalases, and that PCA sensitivity was reduced when $X$. oryzae
\end{abstract}

ABSTRACT pvs. oryzae and oryzicola were cultured with exogenous catalase. Furthermore, cat $B$ deletion mutants of $X$. oryzae pvs. oryzae and oryzicola showed dramatically decreased total catalase activity, increased sensitivity to PCA, and reduced virulence in rice. In contrast, deletion mutants of $\operatorname{srpA}$ and $k a t G$, which also encode catalases, exhibited little change in PCA sensitivity. The results indicate that $c a t B$ in both $X$. oryzae pvs. oryzae and oryzicola encodes a catalase that helps protect the bacteria against PCA-induced stress.

Additional keywords: total catalase activities.
Xanthomonas oryzae pv. oryzae and X. oryzae pv. oryzicola, the causal agents of rice bacterial leaf blight (BLB) and rice bacterial leaf streak (BLS), respectively, are widespread and important pathogens of rice. BLB and BLS can cause up to $75 \%$ yield loss in tropical regions of Asia (Ou 1985). Since 1955, a large number of antibiotics (penicillin, streptomycin, aureomycin, and others) have been used to control BLB and BLS but their application at high rates for long periods of time has resulted in phytotoxicity and in the development of resistance in Xanthomonas spp. (Arata et al. 1961). Therefore, novel bactericides are urgently needed for controlling BLB and BLS.

Phenazines are a large class of secondary metabolites produced by many bacterial species (Mavrodi et al. 2006; Zhou et al. 2016). Yoneyama et al. (1969) were the first to report that phenazines were effective in controlling BLB and had low phytotoxicity. Phenazine-1-carboxylic acid (PCA), a novel phenazine metabolite of Pseudomonas aeruginosa M18, was registered as "Shenqinmycin" in China against rice sheath blight. (Chen et al. 2012; Huang et al. 2016; Ye et al. 2010; Zhang et al. 2015). PCA was also used to control rice blast in Guangdong province of China (Zhou and Zhang 2016). In 2015, Xu et al. (2015) found that PCA was effective against not only various fungal plant pathogens but also against $X$. oryzae pv. oryzicola and especially against $X$. oryzae pv. oryzae. Moreover, PCA has already been used in field control of BLS in the rice-planting region of South China (Zhou et al. 2014).

The mechanism of action of phenazines is associated with their ability to undergo oxidation-reduction transformations that cause the accumulation of reactive oxygen species (ROS) in target cells

Corresponding author: M. Zhou; E-mail address: mgzhou@njau.edu.cn

*The $\boldsymbol{e}$-Xtra logo stands for "electronic extra" and indicates that three supplementary figures and two supplementary tables are published online.

(C) 2017 The American Phytopathological Society
(Laursen and Nielsen 2004). ROS are a large group of highly reactive molecular forms of oxygen carrying unpaired electrons (Riley 1994). ROS include superoxide anion $\left(\mathrm{O}_{2}^{-}\right)$, hydrogen peroxide $\left(\mathrm{H}_{2} \mathrm{O}_{2}\right)$, and hydroxyl radical $\left(\mathrm{OH}^{\bullet}\right)$. These are byproducts of cellular respiration or protein folding or are the end products of a number of metabolic reactions (Reczek and Chandel 2015; Toledano et al. 2010). Among these ROS species, $\mathrm{O}_{2}{ }^{-}$is the most active oxidant and can generate $\mathrm{H}_{2} \mathrm{O}_{2}$ in the presence of superoxide dismutase (Hertzberger et al. 2014; Wang et al. 2015). $\mathrm{H}_{2} \mathrm{O}_{2}$ is considered the most stable ROS species and can generate $\mathrm{OH}^{\bullet}$ through the Fenton reaction (Lu et al. 2013; Pridmore et al. 2008).

Catalases are vital components of the detoxification pathways that convert $\mathrm{H}_{2} \mathrm{O}_{2}$ to water and molecular oxygen (Schouten et al. 2002). Catalases differ among bacterial species. Bacterial catalases have been classified into three types: monofunctional heme-containing catalases, bifunctional heme-containing catalaseperoxidases, and nonheme or Mn-containing catalases (Chelikani et al. 2004; Klotz et al. 1997). Each type of catalase has a different function at different phases of bacterial growth, and catalase levels differ depending on the nature of the environmental stress (Wang et al. 2013a). X. oryzae pv. oryzae has monofunctional hemecontaining catalases, including three enzymes encoded by $c a t B$, $k a t E$, and $\operatorname{srpA}$. X. oryzae pv. oryzicola has three genes that are homologous to the catalase genes of $X$. oryzae pv. oryzae and one other bifunctional heme-containing catalase-peroxidase encoded by $k a t G$.

Although the general mode of action of PCA against X. oryzae pv. oryzae has been described, the detailed interactions between PCA and the catalases of $X$. oryzae pvs. oryzae and oryzicola remain unclear (Xu et al. 2015). In this study, all of the catalases of $X$. oryzae pvs. oryzae and oryzicola were investigated under PCA-induced stress. For this purpose, we generated deletion mutants of all of the catalase genes of $X$. oryzae pvs. oryzae and oryzicola and determined the roles of these catalases in protecting the bacterial cells from PCA. 


\section{MATERIALS AND METHODS}

Bacterial strains, plasmids, bactericides, and culture media. The bacterial strains and plasmids used in this study are listed in Table 1. X. oryzae pvs. oryzae and oryzicola strains were grown at $28^{\circ} \mathrm{C}$ in nutrient broth (NB) medium or on nutrient agar (NA) plates. NA medium consisted of beef extract at $3 \mathrm{~g} /$ liter, yeast extract at $1 \mathrm{~g} / \mathrm{liter}$, polypeptone at $5 \mathrm{~g} / \mathrm{liter}$, sucrose at $10 \mathrm{~g} / \mathrm{liter}$, and agar powder at $12 \mathrm{~g} /$ liter. NB medium contained the same components but lacked agar powder. Nutrient-limiting broth (MMX) medium ( $\mathrm{pH} 7.0$ ) was used as a minimal medium and was prepared with glucose at $5 \mathrm{~g} /$ liter, $\left(\mathrm{NH}_{4}\right)_{2} \mathrm{SO}_{4}$ at $2 \mathrm{~g} / \mathrm{liter}$, $\mathrm{MgSO}_{4} \cdot 7 \mathrm{H}_{2} \mathrm{O}$ at $0.2 \mathrm{~g} /$ liter, $\mathrm{K}_{2} \mathrm{HPO}_{4}$ at $4 \mathrm{~g} / \mathrm{liter}, \mathrm{KH}_{2} \mathrm{PO}_{4}$ at $6 \mathrm{~g} / \mathrm{liter}$, and trisodium citrate at $1 \mathrm{~g} /$ liter. Escherichia coli $\mathrm{DH} 5 \alpha$ was used for vector construction and was cultured in Luria-Bertani (LB) medium or on LB agar plates containing kanamycin at $50 \mu \mathrm{g} /$ ml. PCA (98\%) was provided by the Shanghai Nongle Biological Products Co., Ltd. and was dissolved in acetone as a stock solution.

Determination of transcript levels of catalase genes in X. oryzae pvs. oryzae and oryzicola. ZJ173 and RS105 were used as wild-type strains of $X$. oryzae pvs. oryzae and oryzicola, respectively. All wild-type strains and deletion mutants were cultured to different growth phases (as indicated by optical density at $600 \mathrm{~nm}\left[\mathrm{OD}_{600}\right]$ values) in $\mathrm{NB}$ medium at $28^{\circ} \mathrm{C}$. The bacterial cells were harvested by centrifugation $\left(12,000 \times g\right.$ for 2 min at $\left.4^{\circ} \mathrm{C}\right)$. Total RNA was extracted with the RNAprep pure cell/bacteria kit (TIANGEN Biotech) and was reverse transcribed into cDNA with the PrimeScript RT reagent Kit (TaKaRa) according to the instruction manual. Quantitative real-time polymerase chain reaction (qRT-PCR) was conducted using SYBR Green supermix (Bio-Rad) with an ABI PRISM 7500 Real-Time PCR System (Applied Biosystems). Transcript levels of XOO0417 (catB, AAW73671), XOO3423 (katE, AAW73701), and XOO0447 (srpA, AAW76677) in wild-type and mutant $X$. oryzae pv. oryzae strains and XOC_4325 (catB, AEQ98396), XOC_1265 (katE, AEQ98362), XOC_4290 (srpA, AEQ95453); and XOC_3410 (katG, AEQ97503) in wild-type and mutant $X$. oryzae pv. oryzicola strains (gene names are according to the annotations of X. oryzae pv. oryzae strain KACC 10331 and X. oryzae pv. oryzicola strain BLS256) were assessed. 16S ribosomal RNA was used as the endogenous control. The primer sequences are listed in Supplementary Table $\mathrm{S} 2$.

Construction of a phylogenetic tree. The sequences of all catalases of $X$. oryzae pv. oryzae KACC 10331, X. oryzae pv. oryzicola BLS256, X. campestris pv. campestris ATCC 33913, and $X$. axonopodis pv. citri 306 were searched in the National Center for Biotechnology Information protein database (http://www.ncbi.nlm. nih.gov/protein/). A phylogenetic tree of all catalases aligned with CLUSTALW was constructed using the software MEGA 4.0 (Kumar et al. 2008).

Generation of mutants and complemented strains. To investigate the functions of catalase genes in $X$. oryzae pvs. oryzae and oryzicola, we generated all catalase deletion mutants via a nonmarker homologous recombination method (Yu et al. 2015). pK18mobsacB was used as a suicide vector in this study. The genomic DNA of $X$. oryzae pv. oryzae ZJ173 and $X$. oryzae pv. oryzicola RS105 were used as the templates to amplify the upstream and downstream fragments of all catalase genes. The primers of all upstream and downstream fragments are listed in Supplementary Table S1. The recombinant plasmids listed in Table 1 were

TABLE 1. Strains and plasmids used in this study

\begin{tabular}{|c|c|c|}
\hline Strains and plasmids & Characteristics & Source \\
\hline \multicolumn{3}{|l|}{ Strains } \\
\hline Escherichia coli $\mathrm{DH} 5 \alpha$ & $\varphi 80$ lacZAM15, $\triangle($ lacZYA-argF $) \mathrm{U} 169$. recA1 & Vazyme, Nanjing, China \\
\hline ZJ173 & $\mathrm{Rif}^{\mathrm{R}}$, wild-type strain of Xanthomonas oryzae pv. oryzae & Laboratory collection \\
\hline$\Delta Z / c a t B$ & $\mathrm{Rif}^{\mathrm{R}}$, deletion of catB in wild-type strain $\mathrm{ZJ} 173$ & This study \\
\hline$\Delta Z / k a t E$ & $\mathrm{Rif}^{\mathrm{R}}$, deletion of katE in wild-type strain $\mathrm{ZJ} 173$ & This study \\
\hline$\Delta Z / \operatorname{srp} A$ & $\mathrm{Rif}^{\mathrm{R}}$, deletion of $\operatorname{srpA}$ in wild-type strain $\mathrm{ZJ} 173$ & This study \\
\hline$\Delta Z / \mathrm{catB} / \mathrm{kat} E$ & $\mathrm{Rif}^{\mathrm{R}}$, double deletion of $c a t B$ and $k a t E$ in wild-type strain $\mathrm{ZJ} 173$ & This study \\
\hline$\Delta Z / c a t B($ catB $)$ & $\mathrm{Rif}^{\mathrm{R}}, \mathrm{Km}^{\mathrm{R}}$, complemented strain of $\Delta Z /$ cat $B$ & This study \\
\hline$\Delta Z /$ catB/katE $($ catB $)$ & Rif ${ }^{\mathrm{R}}, \mathrm{Km}^{\mathrm{R}}$, complemented strain of $\Delta Z / \mathrm{catB} / \mathrm{kat} E$ & This study \\
\hline RS105 & $\mathrm{Rif}^{\mathrm{R}}$, wild-type strain of Xanthomonas oryzae pv. oryzicola & This study \\
\hline$\Delta R / c a t B$ & $\mathrm{Rif}^{\mathrm{R}}$, deletion of $c a t B$ in wild-type strain $\mathrm{RS} 105$ & This study \\
\hline$\Delta R / k a t E$ & $\mathrm{Rif}^{\mathrm{R}}$, deletion of katE in wild-type strain RS105 & This study \\
\hline$\Delta R / \operatorname{srp} A$ & $\mathrm{Rif}^{\mathrm{R}}$, deletion of $\operatorname{srp} A$ in wild-type strain RS105 & This study \\
\hline$\Delta R / k a t G$ & $\mathrm{Rif}^{\mathrm{R}}$, deletion of katG in wild-type strain $\mathrm{RS} 105$ & This study \\
\hline$\Delta R / \mathrm{catB} / \mathrm{kat} E$ & $\mathrm{Rif}^{\mathrm{R}}$, double deletion of $c a t B$ and $k a t E$ in wild-type strain $\mathrm{RS} 105$ & This study \\
\hline$\Delta R /$ catB $($ catB $)$ & $\mathrm{Rif}^{\mathrm{R}}, \mathrm{Km}^{\mathrm{R}}$, complemented strain of $\Delta R /$ catB $^{2}$ & This study \\
\hline$\Delta R / \mathrm{catB} / \mathrm{kat} E(\mathrm{catB})$ & $\mathrm{Rif}^{\mathrm{R}}, \mathrm{Km}^{\mathrm{R}}$, complemented strain of $\Delta R / \mathrm{catB} / \mathrm{katE}$ & This study \\
\hline \multicolumn{3}{|l|}{ Plasmids } \\
\hline pK18mobsacB & $\mathrm{Km}^{\mathrm{R}}$, allelic exchange suicide vector, $s a c B$ oriT(RP4) & Laboratory collection \\
\hline pK18ZCB & $\begin{array}{l}\mathrm{Km}^{\mathrm{R}} \text {, a 1,598-bp fusion fragment of ZcatB-1, ZcatB-2gene } \\
\text { ligated in pK18mobsacB }\end{array}$ & This study \\
\hline $\mathrm{pK} 18 \mathrm{ZKE}$ & $\begin{array}{l}\mathrm{Km}^{\mathrm{R}} \text {, a 1,575-bp fusion fragment of ZkatE-1, ZkatE-2gene } \\
\text { ligated in pK18mobsacB }\end{array}$ & This study \\
\hline pK18ZSA & $\begin{array}{l}\mathrm{Km}^{\mathrm{R}} \text {, a 1,520-bp fusion fragment of ZsrpA-1, ZsrpA-2gene } \\
\text { ligated in pK18mobsacB }\end{array}$ & This study \\
\hline $\mathrm{pK} 18 \mathrm{RCB}$ & $\begin{array}{l}\mathrm{Km}^{\mathrm{R}} \text {, a 1,841-bp fusion fragment of RcatB-1, RcatB-2gene } \\
\text { ligated in pK18mobsacB }\end{array}$ & This study \\
\hline $\mathrm{pK} 18 \mathrm{RKE}$ & $\begin{array}{l}\mathrm{Km}^{\mathrm{R}} \text {, a 1,584-bp fusion fragment of RkatE-1, RkatE-2gene } \\
\text { ligated in pK18mobsacB }\end{array}$ & This study \\
\hline pK18RSA & $\begin{array}{l}\mathrm{Km}^{\mathrm{R}} \text {, a 1,414-bp fusion fragment of RsrpA-1, RsrpA-2gene } \\
\text { ligated in pK18mobsacB }\end{array}$ & This study \\
\hline pK18RKG & $\begin{array}{l}\mathrm{Km}^{\mathrm{R}} \text {, a 1,332-bp fusion fragment of } \mathrm{R} k a t G-1, \mathrm{R} k a t G \text {-2gene } \\
\text { ligated in pK18mobsacB }\end{array}$ & This study \\
\hline pHMI & $\mathrm{Sp}^{\mathrm{R}}$, broad-host-range cosmid vector, $\mathrm{pSa}$ ori & Laboratory collection \\
\hline pHMIZCB & $\mathrm{Km}^{\mathrm{R}}, \mathrm{ZcatB}-\mathrm{H}$ gene in $\mathrm{ZJ} 173$ ligated in $\mathrm{pHMI}$ & This study \\
\hline pUFR034 & $\operatorname{lnc} W, \mathrm{Nm}^{\mathrm{R}}, \mathrm{Km}^{\mathrm{R}}, \operatorname{Mob}^{+}, \operatorname{Mob}(p), \operatorname{lacZ} \alpha, \mathrm{PK} 2$ replicon, cosmid & Laboratory collection \\
\hline pUFRRCB & $\mathrm{Km}^{\mathrm{R}}$, RcatB-H gene in RS105 ligated in pUFR034 & This study \\
\hline
\end{tabular}

${ }^{\mathrm{z}} \mathrm{Rif}^{\mathrm{R}}, \mathrm{Km}^{\mathrm{R}}, \mathrm{Sp}^{\mathrm{R}}$, and $\mathrm{Nm}^{\mathrm{R}}$ indicate resistant to rifampicin, kanamycin, spectinomycin, and neomycin, respectively. 
transformed into ZJ173 and RS105 competent cells using an electroporation method ( $\mathrm{Yu}$ et al. 2015), and the cells were subsequently screened on plates of NA medium without sucrose containing kanamycin at $20 \mu \mathrm{g} / \mathrm{ml}$. The colonies were transferred to $25 \mathrm{ml}$ of NB medium without sucrose. After $7 \mathrm{~h}$ of incubation at $28^{\circ} \mathrm{C}, 120 \mu \mathrm{l}$ of suspension was spread on plates of NA medium containing sucrose at $100 \mathrm{~g} /$ liter. The colonies were subsequently confirmed by PCR and Southern hybridization (Roche) using the primers listed in Supplementary Table S1. The confirmed mutants were used for further study. Complemented mutants were constructed using pHMI for $X$. oryzae pv. oryzae and pUFR034 for $X$. oryzae pv. oryzicola. All catalase genes (including predicted promoters) were amplified from the genomic DNA of strains ZJ173 and RS105 with the primers listed in Supplementary Table S1. Promoter prediction and electroporation were described in a previous study (Qian et al. 2013). The promoter was predicted with the website http://www.fruitfly.org/seq_tools/ promoter.html.

Growth curves of deletion mutants in MMX medium and NB medium. Strains were cultured to midlogarithmic phase $\left(\mathrm{OD}_{600}\right.$ of approximately 1.0) in $\mathrm{NB}$ medium at $28^{\circ} \mathrm{C}$ with shaking at $175 \mathrm{rpm}$. Bacterial cells were collected by centrifugation $(5,000 \times g$ for $2 \mathrm{~min}$ ) from $2 \mathrm{ml}$ of culture suspension, and the cell pellets were resuspended in water. A 2-ml volume of cell suspension was then added to $100 \mathrm{ml}$ of MMX medium or NB medium. Bacterial cells were grown at $28^{\circ} \mathrm{C}$ with shaking at $175 \mathrm{rpm}$. The $\mathrm{OD}_{600}$ value was determined with an Eppendorf BioPhotometer Plus every $12 \mathrm{~h}$ in the MMX medium until the stationary stage. The $\mathrm{OD}_{600}$ value was determined with same instrument every $4 \mathrm{~h}$ in NB medium until stationary stage.

PCA inhibition of $X$. oryzae pvs. oryzae and oryzicola as affected by addition of catalase. $X$. oryzae pv. oryzae $\mathrm{ZJ} 173$ and $X$. oryzae pv. oryzicola $\mathrm{RS} 105$ were cultured to midlogarithmic phase $\left(\mathrm{OD}_{600}\right.$ of approximately 1.0$)$ in $\mathrm{NB}$ medium at $28^{\circ} \mathrm{C}$ with shaking at $175 \mathrm{rpm}$. The $\mathrm{OD}_{600}$ value of the bacterial suspension was adjusted to 0.1 with NB medium. A $100-\mu l$ volume of the bacterial suspension was added to $25 \mathrm{ml}$ of NB medium, which was then supplemented with acetone or acetone containing PCA to achieve a final PCA concentration of $0.4 \mu \mathrm{g} / \mathrm{ml}$ in the ZJ173 culture or $16 \mu \mathrm{g} / \mathrm{ml}$ in the RS105 culture and a final acetone concentration of $0.4 \%$ (vol/vol). After that, $0,10,20,40$, or $80 \mathrm{U}$ of catalase were added to the medium for ZJ173 and 0, 20, 40, 80 , or $160 \mathrm{U}$ of catalase were added to the medium for RS105. The cultures were kept at $28^{\circ} \mathrm{C}$ with shaking at $175 \mathrm{rpm}$, and $\mathrm{OD}_{600}$ values were determined after $36 \mathrm{~h}$. The effect of catalase on PCA inhibition of growth was expressed as a percentage of growth inhibition relative to a control that was not treated with PCA.

Determination of catalase activity. All wild-type strains and deletion mutants were cultured to early logarithmic phase $\left(\mathrm{OD}_{600}\right.$ of approximately 0.5$)$ in NB medium. The bacterial cells were collected by centrifugation $\left(8,000 \times g\right.$ for $2 \mathrm{~min}$ at $\left.4^{\circ} \mathrm{C}\right)$ from $2 \mathrm{ml}$ of bacterial cultures. The supernatant was removed, and $200 \mu \mathrm{l}$ of Western and IP Cell Lysis Liquid (Beyotime) was added to resuspend the bacterial cell pellet. After 15 min of incubation, the supernatant was collected by centrifugation $(8,000 \times g$ for $2 \mathrm{~min}$ at $4^{\circ} \mathrm{C}$ ). The protein concentrations were determined with the BCA Protein Concentration Determination Kit (Beyotime). Total catalase activities were then determined with the Catalase Test Kit (Beyotime).

Determination of $\mathrm{H}_{2} \mathrm{O}_{2}$ sensitivity. All wild-type strains and deletion mutants were cultured to midlogarithmic phase $\left(\mathrm{OD}_{600}\right.$ of approximately 1.0) in NB medium, and threefold- and ninefold-diluted suspensions were made with NB medium. NA plates containing $0,0.1$, or $0.25 \mathrm{mM} \mathrm{H}_{2} \mathrm{O}_{2}$ were also prepared. A 5 - $\mu$ l volume of the undiluted or diluted cultures of each strain was spotted onto NA plates (in triplicate), and the plates were kept for $36 \mathrm{~h}$ at $28^{\circ} \mathrm{C}$ (Lan et al. 2010). $\mathrm{H}_{2} \mathrm{O}_{2}$ sensitivity was assessed based on colony growth. This experiment was repeated three times.

Determination of PCA sensitivity. All wild-type strains and deletion mutants were grown to midlogarithmic phase $\left(\mathrm{OD}_{600}\right.$ of approximately 1.0) in $\mathrm{NB}$ medium at $28^{\circ} \mathrm{C}$ with shaking at $175 \mathrm{rpm}$. The bacterial suspensions were diluted to $\mathrm{OD}_{600}$ of approximately 0.25 by adding NB medium. A $120-\mu 1$ volume of the diluted bacterial suspension was then added to $25 \mathrm{ml}$ of fresh NB medium containing PCA at $0,0.025,0.05,0.1,0.2,0.4$, or $0.8 \mu \mathrm{g} / \mathrm{ml}$ (final acetone concentration $0.4 \%$ [vol/vol]) for $X$. oryzae $\mathrm{pv}$. oryzae suspensions, and containing PCA at $0,1,2,4,8,16$, or $32 \mu \mathrm{g} / \mathrm{ml}$ (final acetone concentration $0.4 \%$ [ $\mathrm{vol} / \mathrm{vol}]$ ) for $X$. oryzae $\mathrm{pv}$. oryzicola suspensions. Three replicates for each concentration were used for each strain. Bacterial cells were grown at $28^{\circ} \mathrm{C}$ with shaking at $175 \mathrm{rpm}$ for $36 \mathrm{~h}$ for $X$. oryzae pv. oryzae and $24 \mathrm{~h}$ for $X$. oryzae pv. oryzicola before $\mathrm{OD}_{600}$ values were determined. For each strain, the average $\mathrm{OD}_{600}$ values were used to calculate the PCA concentration that resulted in $50 \%$ inhibition of bacterial cell growth $\left(\mathrm{EC}_{50}\right)$. The $\mathrm{EC}_{50}$ values were calculated with the Data Processing System computer program (Hangzhou Reifeng Information Technology Ltd.). Each experiment was done three times.

Virulence assays and determination of numbers of $X$. oryzae pvs. oryzae and oryzicola in rice plants. A pathogenicity assay was conducted in an illuminated growth incubator at $25^{\circ} \mathrm{C}$ with susceptible rice IR24. The bacterial suspensions were inoculated on rice according to a previous study (Yang and Bogdanove 2013), with slight modifications. X. oryzae pvs. oryzae and oryzicola strains were cultivated in $\mathrm{NB}$ medium at $28^{\circ} \mathrm{C}$ and $175 \mathrm{rpm}$ to approximately $10^{9} \mathrm{CFU} / \mathrm{ml}$ for inoculation. Six-week-old rice leaves were clipped with sterile scissors that had been dipped in bacterial suspensions of $X$. oryzae pv. oryzae strains. Leaves of 8-week-old rice plants were inoculated with $X$. oryzae pv. oryzicola strains by piercing the leaves with a needle that had been dipped in the bacterial suspension. Two leaves in each of 10 replicate plants were inoculated for each strain. Lesion lengths were measured 10 days postinoculation (dpi). Each plant represented a biological replicate. The average number of bacterial CFU per square centimeter of rice leaf tissue was determined immediately after inoculation of each $X$. oryzae pv. oryzae and $X$. oryzae pv. oryzicola strain and at 3 dpi. Samples $\left(2 \mathrm{~cm}^{2}\right)$ from the inoculation sites of three leaves were cut and surface sterilized in $5 \% \mathrm{H}_{2} \mathrm{O}_{2}$. Each leaf represented a biological replicate. The samples were ground in $1 \mathrm{ml}$ of sterile water and CFU numbers were determined following plating of serially diluted samples.

Data analysis. All analyses were conducted using SPSS 20.0 (SPSS Inc.). Statistical differences of gene expression, catalase activity, virulence assays, and bacterial numbers in planta were detected with independent-sample $t$ tests. Inhibition of growth by PCA and PCA sensitivity of $X$. oryzae pvs. oryzae and oryzicola were analyzed with one-way analysis of variance (Fisher's least significant difference test).

\section{RESULTS}

Transcript levels of all catalase genes in $X$. oryzae pvs. oryzae and oryzicola at different growth phases. Transcript levels of catalase genes in X. oryzae pv. oryzae ZJ173 and X. oryzae pv. oryzicola RS105 differed among genes and growth phases in NB medium (Fig. 1). When the $\mathrm{OD}_{600}$ value increased to approximately 1 for $X$. oryzae pv. oryzae, the transcript levels increased twofold for katE but had not significantly changed for $\operatorname{srpA}$ (Fig. 1A). Surprisingly, the transcript levels of catB in $X$. oryzae pv. oryzae were the highest at $\mathrm{OD}_{600}$ of approximately 0.2 and thereafter rapidly decreased (Fig. 1A). In X. oryzae pv. oryzicola, the transcript levels of $c a t B$ and katE were lowest at $\mathrm{OD}_{600}$ of approximately 0.2 and then increased 1.2- to 3.0-fold at later growth 
phases (Fig. 1B). Transcript levels of $\operatorname{srpA}$ and katG in X. oryzae pv. oryzicola were the lowest at $\mathrm{OD}_{600}$ of approximately 0.4 (Fig. 1B).

Effect of exogenous PCA on transcript levels of catalase genes in $X$. oryzae pvs. oryzae and oryzicola. qRT-PCR revealed that, in $X$. oryzae pv. oryzae ZJ173, catB and katE were 13.8- and 4.2-fold upregulated, respectively, in response to exogenous PCA (Fig. 2A). In X. oryzae pv. oryzicola RS105, catB and katE were 5.5and 2.1-fold upregulated, respectively, in response to exogenous PCA (Fig. 2B). In contrast, transcript levels of $\operatorname{srp} A$ were unchanged by exogenous PCA in both strains (Fig. 2A and B), and transcript levels of kat $G$ were unchanged in X. oryzae pv. oryzicola (Fig. 2B).

PCA inhibition and catalase transcript levels of $X$. oryzae pvs. oryzae and oryzicola as affected by exogenous catalase. PCA inhibition of growth in culture of $X$. oryzae pv. oryzae $\mathrm{ZJ} 173$ and $X$. oryzae pv. oryzicola $\mathrm{RS} 105$ was reduced by addition of catalase (Fig. 3A and B). In addition, the transcript levels of catB and katE induced by PCA treatment were reduced by addition of catalase (Fig. 3C and D).

Sequence analysis, deletion, and complementation of catalase genes in $X$. oryzae pvs. oryzae and oryzicola. The catalase family consists of catB (XOO0417), katE (XOO3423), and srpA (XOO0447) in X. oryzae pv. oryzae and catB (XOC_4325), katE (XOC_1265), srpA (XOC_4290), and katG (XOC_3410) in
$X$. oryzae pv. oryzicola (gene numbers are according to the annotations of $X$. oryzae pv. oryzae KACC 10331 and X. oryzae pv. oryzicola BLS256, respectively). catB, katE, and $\operatorname{srp} A$ are highly conserved in $X$. oryzae pvs. oryzae and oryzicola (Supplementary Fig. S1). These genes are present at different locations in the genome of X. oryzae pvs. oryzae and oryzicola (http://www.genome. $\mathrm{jp} / \mathrm{kegg} /$ ).

To investigate the functions of catalase genes in $X$. oryzae pvs. oryzae and oryzicola under PCA-induced stress, we generated targeted deletion mutants by a nonmarker homologous recombination method in the background of strains ZJ173 and RS105, respectively. Deletion strains were verified by PCR using different primer combinations (Supplementary Fig. S2A). Southern blot analyses with 500- to 800-bp DNA fragment probes confirmed the deletion mutants (Supplementary Fig. S2B). In addition, qRT-PCR analysis of RNA extracted from the mutants showed that they had completely lost expression of the target transcripts (Fig. 4). $\Delta Z /$ cat $B$ and $\Delta Z /$ catB/katE mutants of $X$. oryzae pv. oryzae ZJ173 and $\Delta R /$ cat $B$ and $\Delta R / c a t B / k a t E$ mutants of $X$. oryzae pv. oryzicola $\mathrm{RS} 105$ were complemented with plasmids pHMI and pUFR034 carrying the open reading frames of $c a t B$ and its predicted promoter of $\mathrm{ZJ} 173$ and RS105, respectively. Complementation of the mutants was confirmed by PCR (Supplementary Fig. S2C).
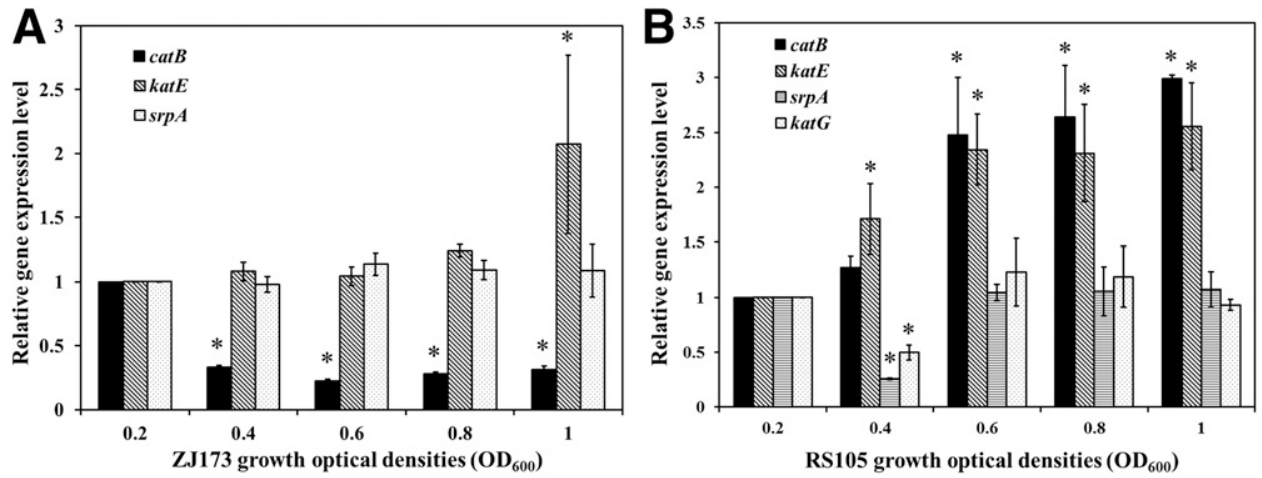

Fig. 1. Transcript levels of all catalase genes at different growth phases in A, Xanthomonas oryzae pv. oryzae strain ZJ173 and $\mathbf{B}, X$. oryzae pv. oryzicola strain RS105 as determined by quantitative real-time polymerase chain reaction analysis. RNA extracts were obtained from nutrient broth cultures at optical density at $600 \mathrm{~nm}\left(\mathrm{OD}_{600}\right)=0.2,0.4,0.6,0.8$, and 1.0 and $28^{\circ} \mathrm{C}$. Columns and vertical bars indicate the means and standard errors of three independent experiments. Each independent experiment included three biological replicates and three technical replicates. Similar results were obtained from three independent experiments. Asterisks indicate a significant difference relative to the expression at $\mathrm{OD}_{600}$ of approximately 0.2 in independent-sample $t$ tests $(P<0.05)$.
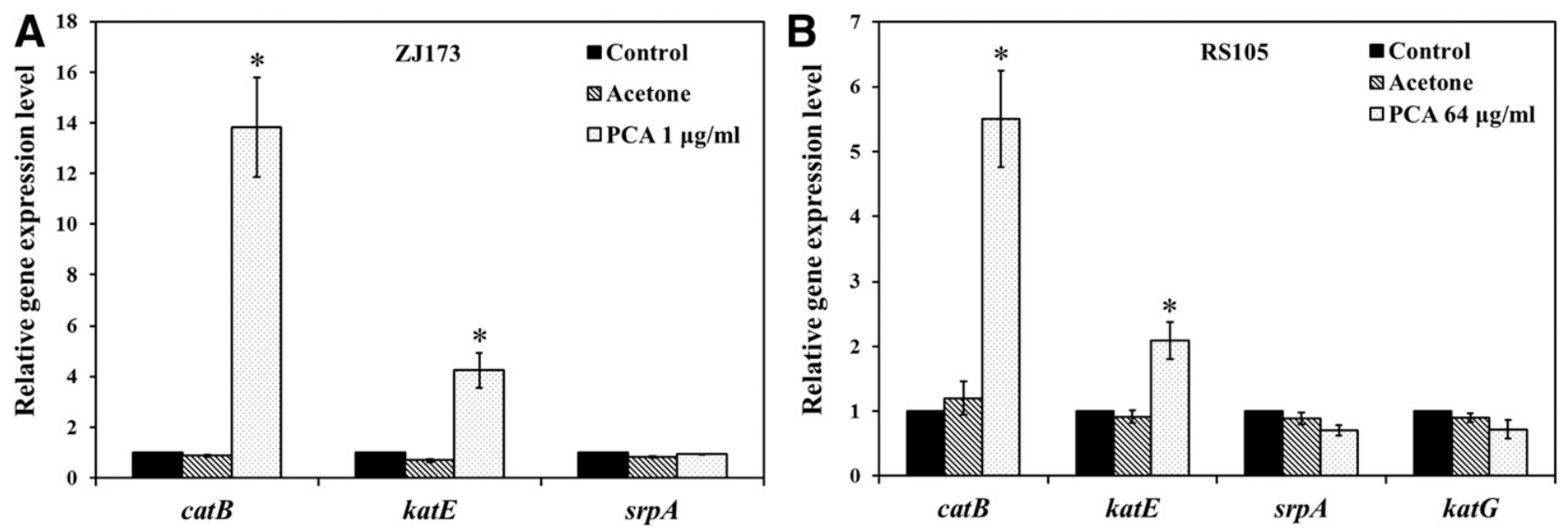

Fig. 2. Transcript levels of catalase genes in A, Xanthomonas oryzae pv. oryzae strain ZJ173 and B, X. oryzae pv. oryzicola strain RS105 in response to exogenous phenazine-1-carboxylic acid (PCA) $(1 \mu \mathrm{g} / \mathrm{ml}$ for ZJ173 and $64 \mu \mathrm{g} / \mathrm{ml}$ for RS105) as determined by quantitative real-time polymerase chain reaction analysis. RNA extracts were obtained from nutrient broth cultures at $28^{\circ} \mathrm{C}$ containing PCA + acetone, acetone alone, or neither (control). Columns and vertical bars indicate the means and standard errors of three independent experiments. Each independent experiment included three biological replicates and three technical replicates. Similar results were obtained from three independent experiments. Asterisks indicate a significant difference relative to control in independent-sample $t$ tests $(P<0.05)$ 
Growth of catalase deletion and complemented mutants. The growth rates of all mutants were determined in MMX and $\mathrm{NB}$ media. The $X$. oryzae pv. oryzae ZJ173 mutants $\Delta Z /$ catB and $\Delta Z / c a t B / k a t E$ could not grow in MMX (Fig. 5A). The $X$. oryzae pv. oryzicola RS105 mutant $\Delta R /$ catB/katE could not grow in MMX medium, and the $\Delta R /$ cat $B$ mutant grew slowly in this medium (Fig. $5 \mathrm{~B})$. The other deletion mutants of both strains grew normally in MMX medium. If growth of deletion mutants in MMX medium was reduced, it was restored by complementation (Fig. 5A and B). All catalase deletion mutants exhibited a growth rate similar to that of the wild-type strains in NB medium (Fig. 5C).

Transcript levels of catalase genes in $X$. oryzae pvs. oryzae and oryzicola deletion mutants. As expected, expression of the catalase genes was not detected in mutant strains deleted in the corresponding genes (Fig. 4). Deletion of a catalase gene caused transcriptional changes of other catalase genes in NB medium. cat $B$ deletion increased $k a t E$ expression levels by 8.6-fold in $X$. oryzae pv. oryzae $\mathrm{ZJ} 173$ and by 3.9 -fold in $X$. oryzae pv. oryzicola RS105. In $X$. oryzae pv. oryzae ZJ173 mutant $\Delta Z / k a t E$, cat $B$ transcription was upregulated by 1.5 -fold, whereas $\operatorname{srp} A$ transcription was downregulated by 1.2 -fold. In $X$. oryzae pv. oryzicola RS105 mutant $\Delta R / k a t E$, catB and $\operatorname{srp} A$ transcriptions were upregulated by 1.4- and 1.3-fold, respectively, whereas $k a t G$ transcription was downregulated by 2 -fold. In $X$. oryzae pv. oryzae ZJ173 mutant $\Delta Z /$ srpA and $X$. oryzae pv. oryzicola RS105 mutant $\Delta R / \operatorname{srp} A$, cat $B$ transcription was slightly upregulated, whereas $k a t E$ and $k a t G$ transcription was slightly downregulated. $k a t G$ deletion in $X$. oryzae pv. oryzicola RS105 had little influence on other genes.
katE transcription was upregulated by 2.2 -fold in $X$. oryzae pv. oryzae ZJ173 mutant $\Delta \mathrm{Z} / \mathrm{catB} / \mathrm{katE}$ compared with $X$. oryzae pv. oryzae ZJ173 and by 1.7 -fold in $X$. oryzae pv. oryzicola $\mathrm{RS} 105$ mutant $\Delta R / c a t B / k a t E$ compared with $X$. oryzae $\mathrm{pv}$. oryzicola RS105.

Catalase activity in mutants and complemented strains of $X$. oryzae pvs. oryzae and oryzicola. Catalase activity was significantly lower in $X$. oryzae pv. oryzae ZJ173 mutants $\Delta Z /$ catB and $\Delta Z /$ catB/kat than in the wild-type strain (Fig. 6A). Similarly, catalase activity was significantly lower in $X$. oryzae pv. oryzicola RS105 mutants $\Delta R /$ cat $B$ and $\Delta R /$ catB/kat $E$ than in wild-type strain RS105 (Fig. 6B). In contrast, the catalase activity of the other deletion and complemented mutants did not significantly differ from the activity in the corresponding wild-type strains.

Effects of catalase genes on $X$. oryzae pvs. oryzae and oryzicola sensitivity to $\mathrm{H}_{2} \mathrm{O}_{2}$ or PCA. $\Delta Z /$ catB and $\Delta Z /$ catB/ kat $E$ mutants were more sensitive to $\mathrm{H}_{2} \mathrm{O}_{2}$ than wild-type $X$. oryzae pv. oryzae ZJ173 (Fig. 7A). As expected, tolerance to $\mathrm{H}_{2} \mathrm{O}_{2}$ was partially restored in the complemented mutants $\Delta Z /$ catB $($ cat $B)$ and $\Delta Z /$ cat $B / k a t E$ (catB). Similarly, $\Delta R /$ cat $B$ and $\Delta R /$ cat $B /$ kat $E$ mutants were more sensitive to $\mathrm{H}_{2} \mathrm{O}_{2}$ than wild-type $X$. oryzae pv. oryzicola RS105. Colony growth of mutants $\Delta R /$ catB and $\Delta R /$ catB/katE was also inhibited when $\mathrm{H}_{2} \mathrm{O}_{2}$ concentration reached $0.25 \mathrm{mM}$ (Fig. 7B).

To further verify whether the disruption of catalase genes increases PCA sensitivity in $X$. oryzae pvs. oryzae and oryzicola, we performed bacterial sensitivity tests. $\mathrm{EC}_{50}$ values were significantly lower for all $c a t B$ deletion mutants than for the wild-type strains of
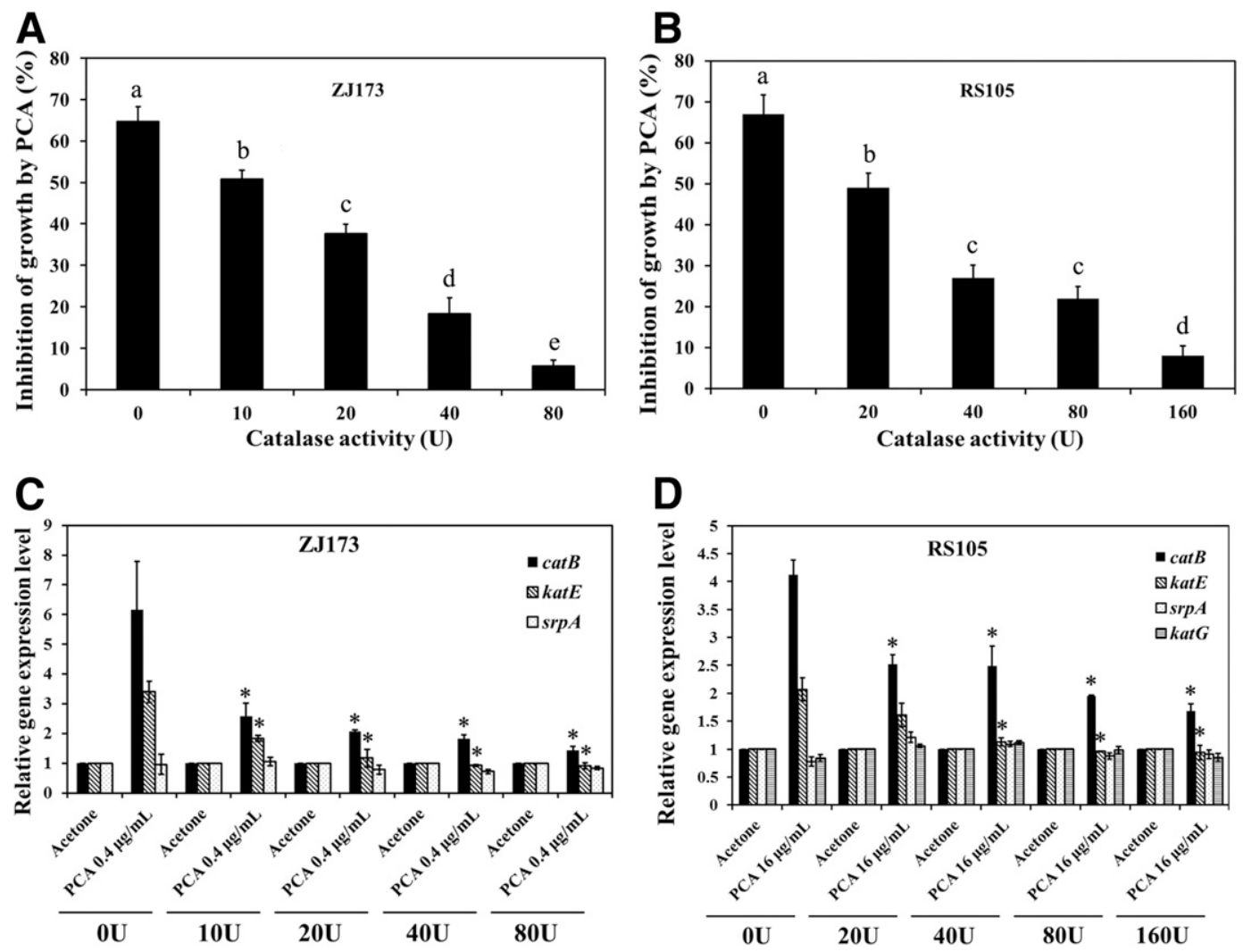

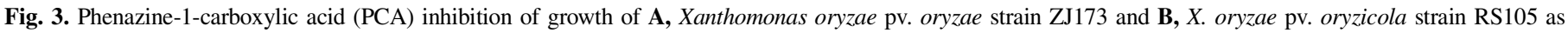

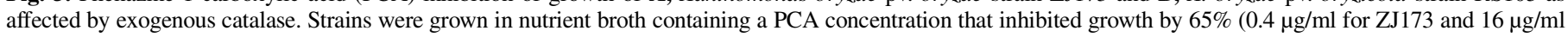

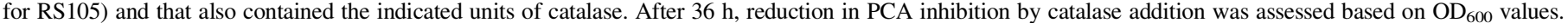

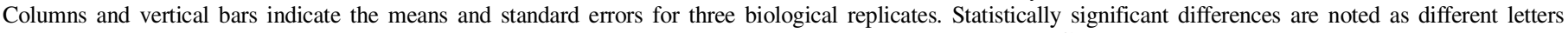

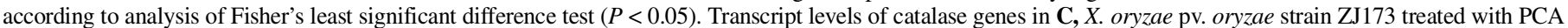

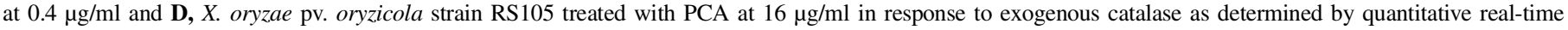

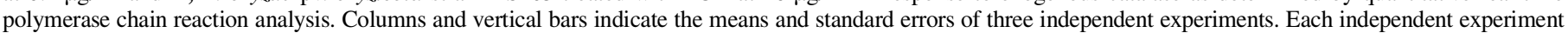

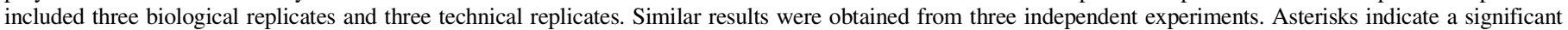
difference from $0.4 \mu \mathrm{g} / \mathrm{ml}$ PCA in $\mathrm{C}$ and $16 \mu \mathrm{g} / \mathrm{ml}$ in D without any exogenous catalase in independent-sample $t$ tests $(P<0.05)$. 

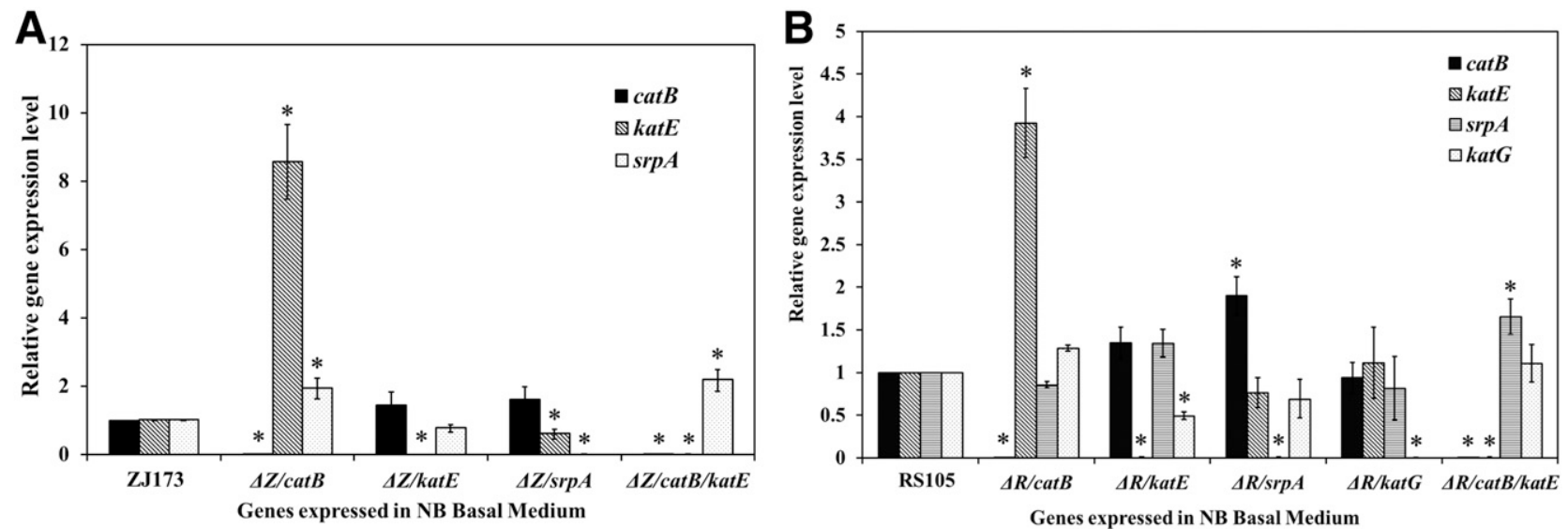

Fig. 4. Relative transcript levels of catalase genes in A, Xanthomonas oryzae pv. oryzae ZJ173 and B, X. oryzae pv. oryzicola strain RS015 and their catalase deletion mutants, as determined by quantitative real-time polymerase chain reaction analysis. NB = nutrient broth. Columns and vertical bars indicate the means and standard errors of three independent experiments. Each independent experiment included three biological replicates and three technical replicates. Similar results were obtained from three independent experiments. Asterisks indicate a significant difference relative to the corresponding wild-type strains in independentsample $t$ tests $(P<0.05)$.

A

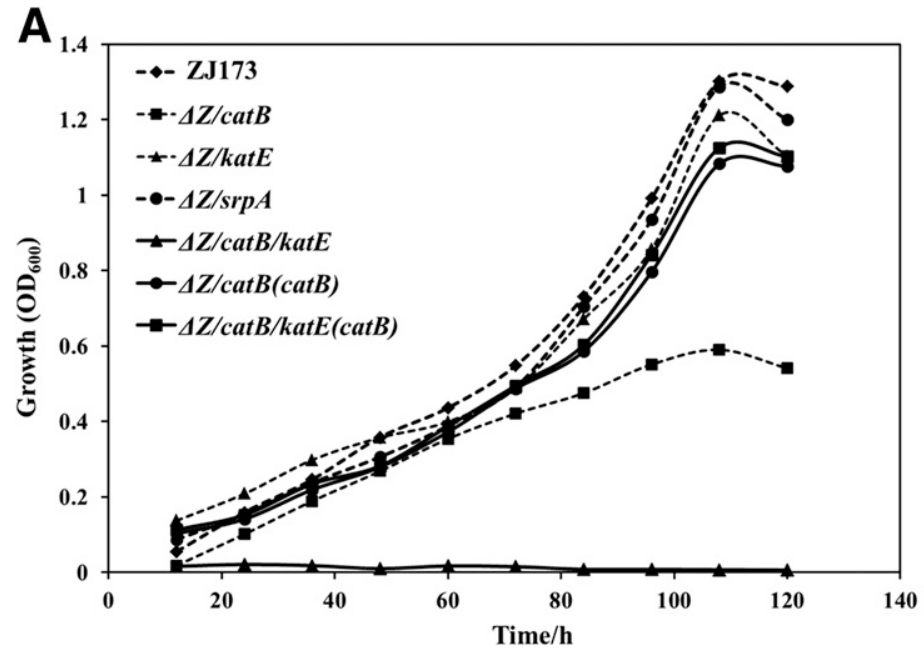

C

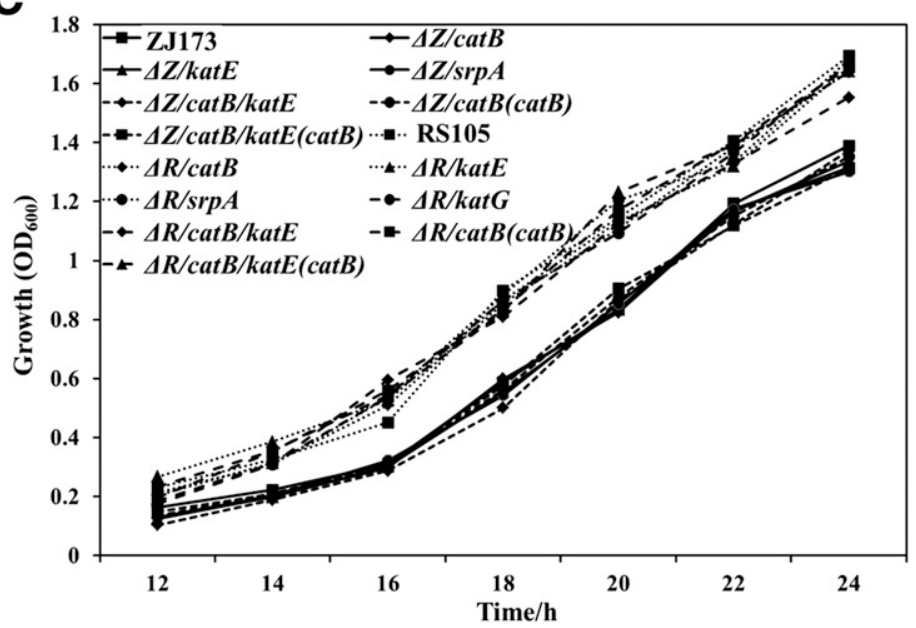

Fig. 5. Growth of wild-type strains, catalase deletion mutants, and complemented mutants of Xanthomonas oryzae pv. oryzae ZJ173 and X. oryzae pv. oryzicola RS105 in a nutrient-poor medium (MMX) and a nutrient-rich medium (NB), as indicated by optical density at $600 \mathrm{~nm}\left(\mathrm{OD}_{600}\right)$. A, Growth rate in MMX of the $X$. oryzae pv. oryzae ZJ173; the catalase deletion mutants $\Delta Z /$ catB, $\Delta Z / k a t E, \Delta Z / s r p A$, and $\Delta Z /$ cat $B / k a t E$; and their complemented mutants $\Delta Z / c a t B($ catB $)$ and $\Delta Z /$ catB/katE(catB). B, Growth rate in MMX of the X. oryzae pv. oryzicola RS105; the catalase deletion mutants $\Delta R /$ cat $B, \Delta R / k a t E, \Delta R /$ srpA, $\Delta R / k a t G$, and $\Delta R /$ $c a t B / k a t E$; and their complemented mutants $\Delta R / c a t B(c a t B)$ and $\Delta R / c a t B / k a t E($ catB). C, Growth rate in $\mathrm{NB}$ of $X$. oryzae pv. oryzae ZJ173 and $X$. oryzae pv. oryzicola RS105, their catalase deletion mutants, and their complemented mutants. 

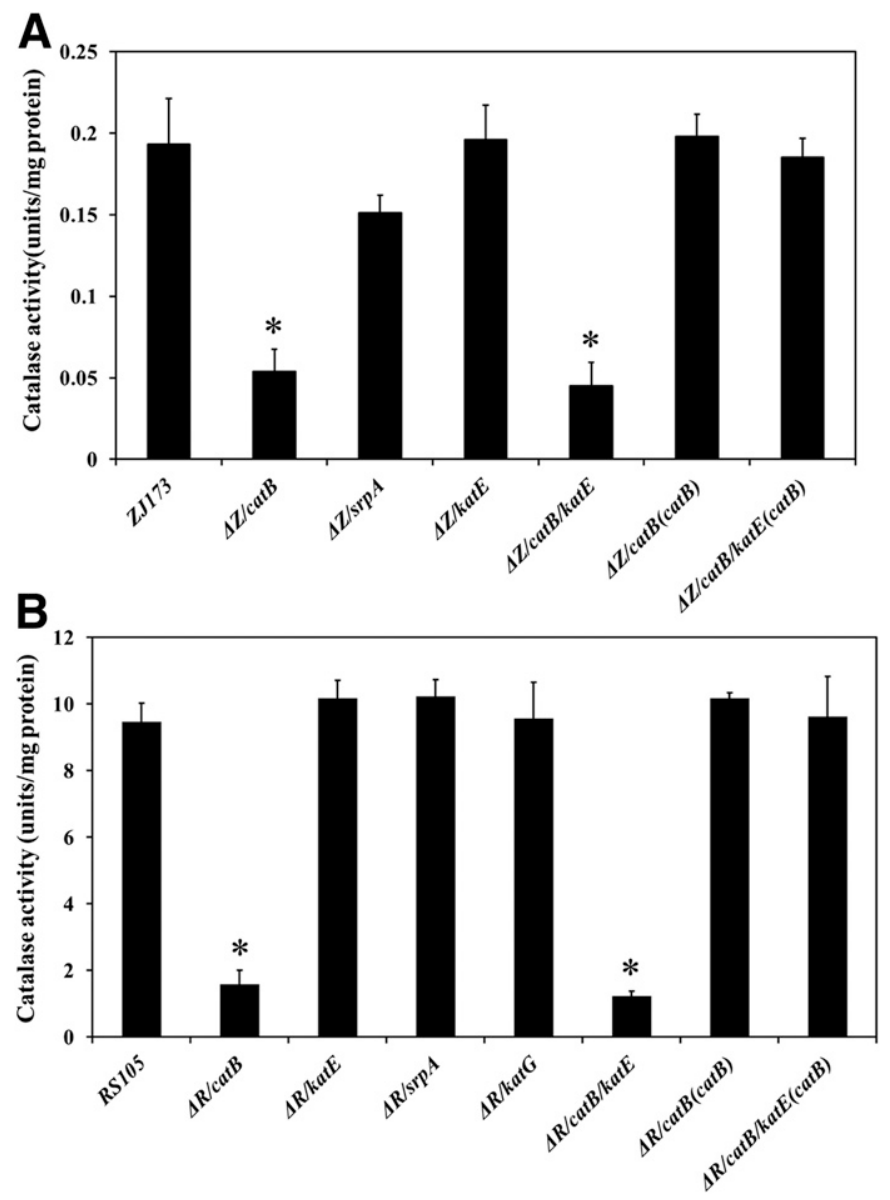

Fig. 6. Total catalase activity from total crude protein extract of $\mathbf{A}$, Xanthomonas oryzae pv. oryzae ZJ173 and B, X. oryzae pv. oryzicola RS015, and their catalase deletion and complemented mutants. Columns and vertical bars indicate the means and standard errors of three independent experiments. Each independent experiment included three biological replicates and three technical replicates. Similar results were obtained from three independent experiments. Asterisks indicate a significant difference relative to the corresponding wild-type strains in independent-sample $t$ tests $(P<0.05)$.
$X$. oryzae pvs. oryzicola and oryzae (ZJ173 and RS105, respectively) (Table 2). In contrast, $\mathrm{EC}_{50}$ values of mutants impaired in other catalase genes were slightly lower but did not significantly differ from the $\mathrm{EC}_{50}$ values of the corresponding wildtype strains.

Virulence of $X$. oryzae pvs. oryzae and oryzicola catalase mutants and complemented strains on rice. Relative to the virulence of $X$. oryzae pv. oryzae $\mathrm{ZJ} 173$, the virulence of mutants $\Delta Z /$ cat $B$ and $\Delta Z /$ cat $B /$ kat $E$ was significantly reduced, whereas the other mutants of ZJ173 were not affected in this feature under tested conditions (Fig. 8A and B). Similarly, the virulence of the $X$. oryzae pv. oryzicola RS105 mutants $\Delta R /$ catB and $\Delta R /$ catB/katE was dramatically reduced, whereas the other mutants of RS105 were not affected in virulence under tested conditions (Fig. 8C and D).

At $3 \mathrm{dpi}$, bacterial numbers of mutants $\Delta Z / \mathrm{cat} B$ and $\Delta Z / \mathrm{catB} / \mathrm{kat} E$ were significantly lower than those of wild-type ZJ173 and the complemented strains (Fig. 8E). Similarly, at 3 dpi, bacterial numbers of mutants $\Delta R / \mathrm{catB}$ and $\Delta R / \mathrm{catB} / \mathrm{katE}$ were also lower than those of wild-type RS105 and the complemented mutants (Fig. 8F).

TABLE 2. Sensitivity of Xanthomonas oryzae pvs. oryzae and oryzicola strains to phenazine-1-carboxylic acid

\begin{tabular}{|c|c|}
\hline Strain & $\mathrm{EC}_{50}(\mu \mathrm{g} / \mathrm{ml})^{\mathrm{z}}$ \\
\hline ZJ173 & $0.181 \pm 0.0155$ a \\
\hline$\Delta Z / c a t B$ & $0.132 \pm 0.0349 b$ \\
\hline$\Delta Z / k a t E$ & $0.179 \pm 0.0120 \mathrm{a}$ \\
\hline$\Delta Z / s r p A$ & $0.156 \pm 0.0158 \mathrm{a}$ \\
\hline$\Delta Z /$ catB/katE & $0.133 \pm 0.0412 b$ \\
\hline$\Delta Z / c a t B($ catB $)$ & $0.168 \pm 0.0212 \mathrm{a}$ \\
\hline$\Delta Z /$ catB/katE(catB) & $0.162 \pm 0.0158 \mathrm{a}$ \\
\hline RS105 & $13.112 \pm 0.192$ a \\
\hline$\Delta R /$ catB & $8.342 \pm 0.581 \mathrm{~b}$ \\
\hline$\Delta R / k a t E$ & $10.881 \pm 1.081 \mathrm{a}$ \\
\hline$\Delta R / \operatorname{srp} A$ & $10.212 \pm 1.234 \mathrm{a}$ \\
\hline$\Delta R /$ katG & $10.325 \pm 0.788 \mathrm{a}$ \\
\hline$\Delta R /$ catB/katE & $8.280 \pm 1.024 b$ \\
\hline$\Delta R /$ catB $($ cat $B)$ & $12.451 \pm 1.564 \mathrm{a}$ \\
\hline$\Delta R /$ catB/katE $($ catB $)$ & $11.032 \pm 1.111 \mathrm{a}$ \\
\hline
\end{tabular}

${ }^{\mathrm{z}}$ Values are means \pm standard errors of three biological independent experiments. Similar results were obtained from three biological independent experiments. Means in a column followed by different letters are significantly different according to Fisher's least significant difference test $(P<0.05)$.

A
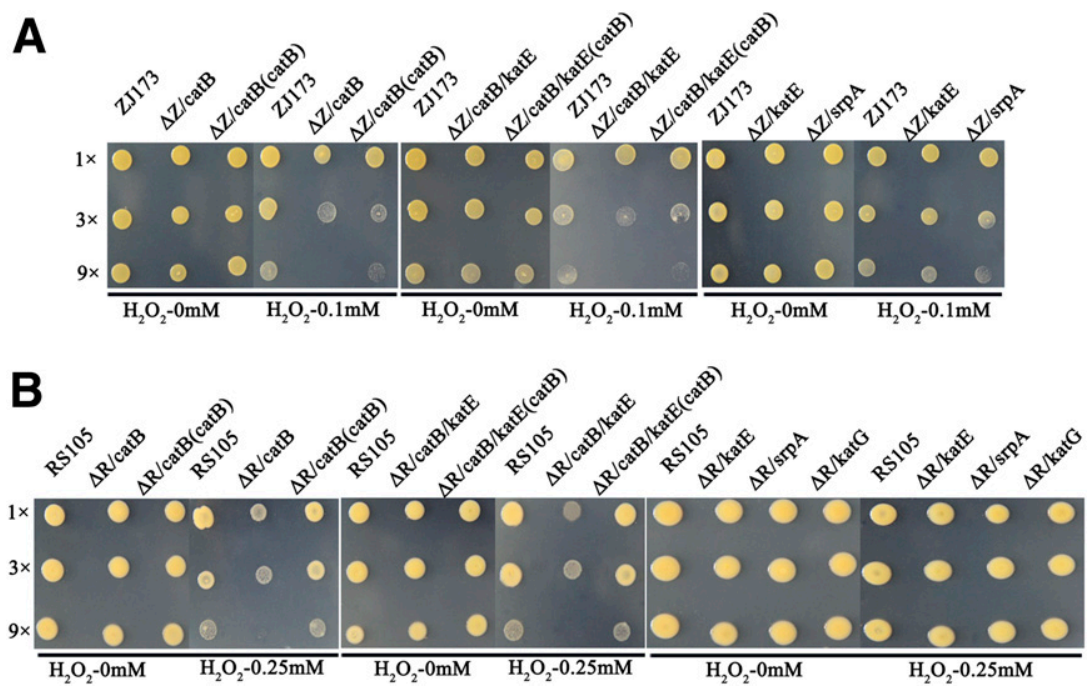

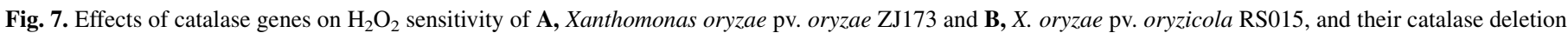

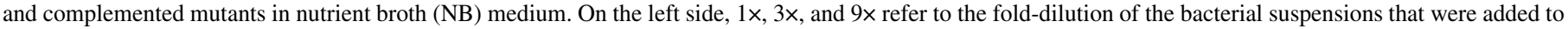
NB medium. 
The other mutants did not differ in bacterial numbers from their corresponding wild-type strains at $3 \mathrm{dpi}$.

\section{DISCUSSION}

Phenazine derivatives of redox-active compounds from $P$. aeruginosa were previously reported to alter the oxidative metabolism or to increase the formation of ROS in E. coli (Hassan and Fridovich 1979). PCA, a secondary metabolite of $P$. aeruginosa, increased oxidant accumulation and altered gene expression, including the expression of genes encoding extracellular catalase in human airway epithelial cells (Look et al. 2005). Xu et al. (2015) also found that PCA increased the accumulation of ROS and reduced catalase activity in $X$. oryzae pv. oryzae. However, a detailed understanding of the antioxidative functions of catalases in $X$. oryzae pvs. oryzae and oryzicola has not been well documented.

Most bacteria have various catalases that are encoded by different genes and that function at different growth phases or under different environmental conditions, suggesting that they may be independent of each other and may differ in phylogeny, structure, and function (Switala et al. 1990; Wang et al. 2013a). The results of the current study indicate that cat $B$ is a critical catalase gene in $X$. oryzae pvs. oryzae and oryzicola. Deletion of $c a t B$ resulted in increased sensitivity to $\mathrm{H}_{2} \mathrm{O}_{2}$ and PCA and reduced virulence in both bacteria.
The transcript levels of $c a t B$ and katE in X. oryzae pvs. oryzae and oryzicola differed greatly depending on growth phase (Fig. 1), indicating that $c a t B$ and $k a t E$ encode the catalases that are largely responsible for $\mathrm{H}_{2} \mathrm{O}_{2}$ scavenging during the growth of $X$. oryzae pvs. oryzae and oryzicola. The expression of $c a t B$ was downregulated in $X$. oryzae pv. oryzae but was upregulated in $X$. oryzae pv. oryzicola after the lag phase, which may explain why total catalase activity was lower for $X$. oryzae pv. oryzae than for $X$. oryzae pv. oryzicola (Fig. 6). We also found that X. oryzae pv. oryzicola was less sensitive to PCA than X. oryzae pv. oryzae, which suggested that catalase activity may be closely related to PCA sensitivity. In response to exogenous PCA, expression of $c a t B$ and $k a t E$ was significantly increased in $X$. oryzae pvs. oryzae and oryzicola (Fig. 2). Moreover, other oxidative stress agents such as clofazimine and paraquat could also increase the expression of $c a t B$ and katE in X. oryzae pvs. oryzae and oryzicola (Supplementary Fig. S3). We inferred that PCA increased the intracellular ROS levels and thereby induced expression of genes involved in cell detoxification, which partially agrees with previous report regarding the mechanism by which PCA inhibits Phellius noxius (Huang et al. 2016). In support of this inference, addition of catalase to the growth medium reduced PCA sensitivity and suppressed the increased expression of catalase in response to PCA in $X$. oryzae pvs. oryzae and oryzicola (Fig. 3).
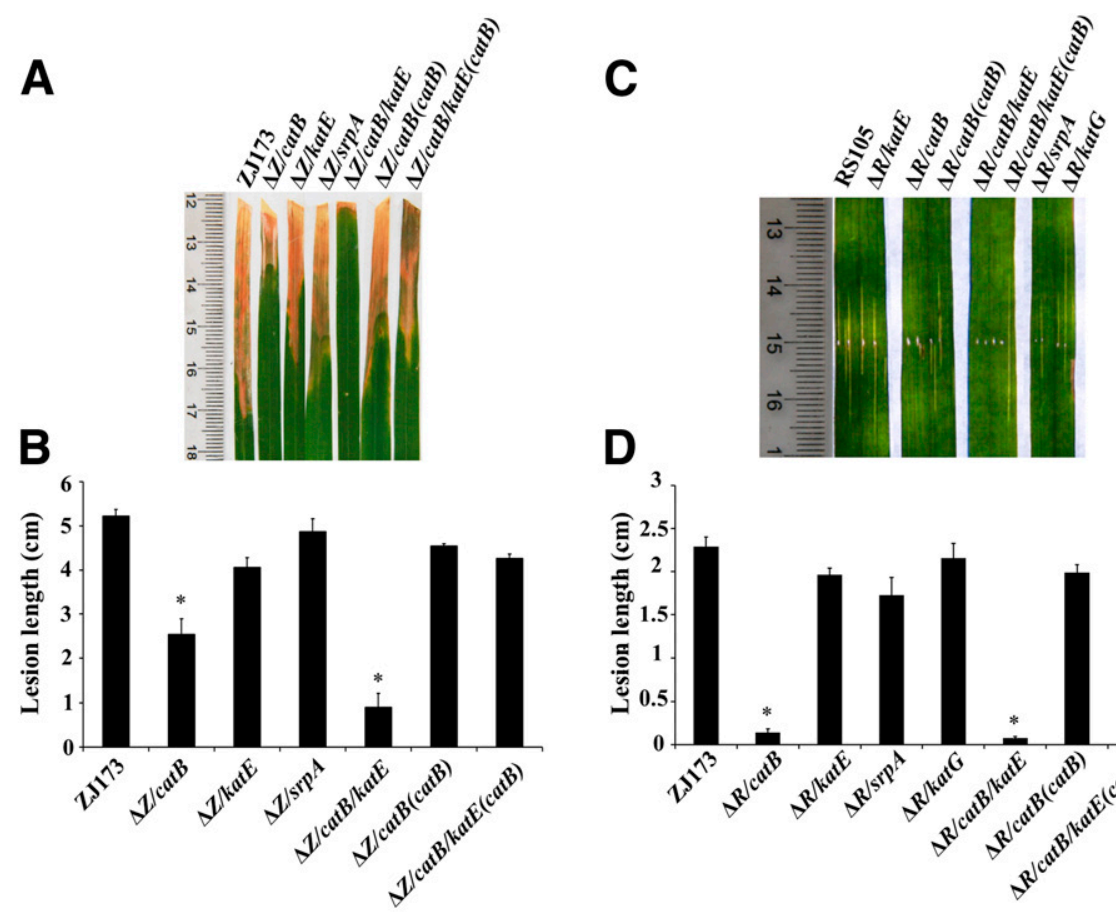

E
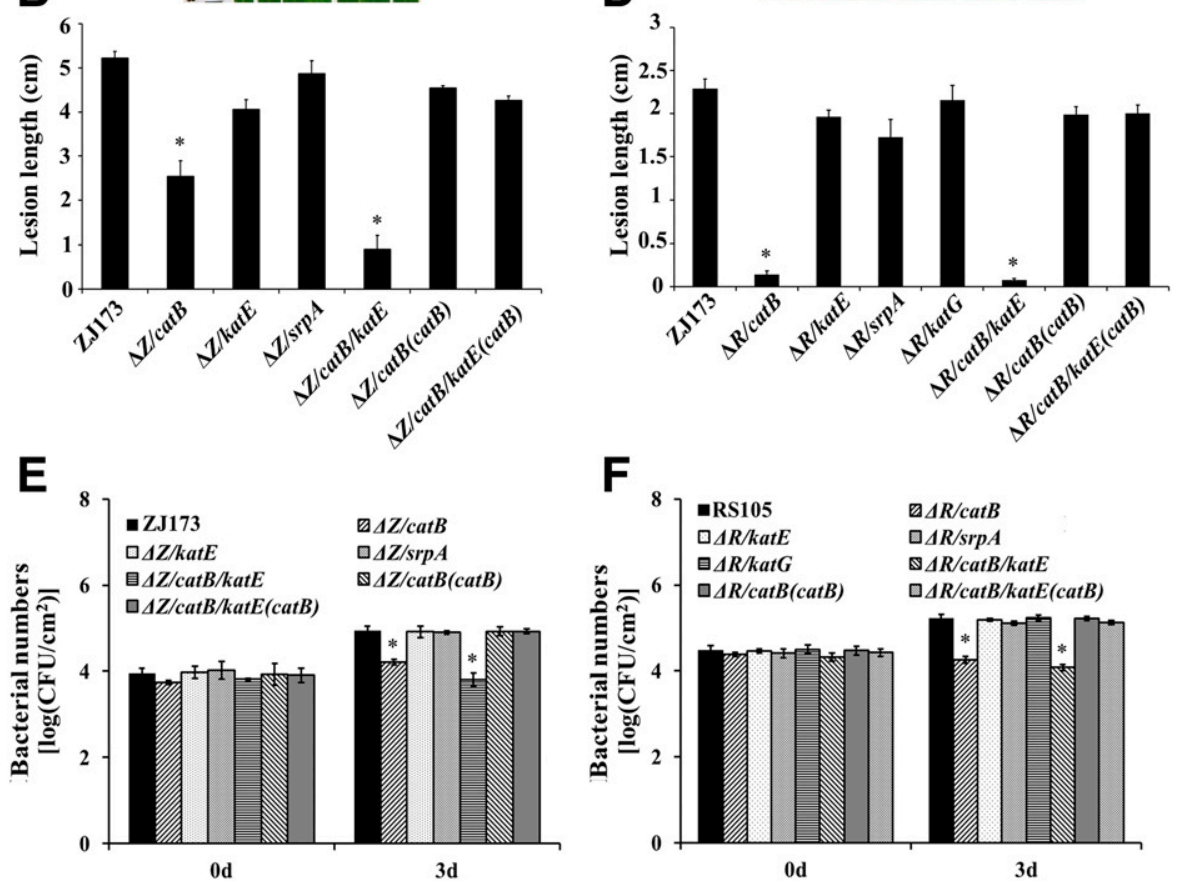

Fig. 8. Virulence of Xanthomonas oryzae pv. oryzae ZJ173, X. oryzae pv. oryzicola RS105, and their catalase deletion and complemented mutants on IR24 rice. A and $\mathbf{C}$, Representative images of rice leaves inoculated with the indicated strains at 10 days postinoculation (dpi). $\mathbf{B}$ and $\mathbf{D}$, Length of lesions caused by all tested strains on rice leaves at 10 dpi. Columns and vertical bars indicate the means and standard errors of 10 biological replicates. Asterisks indicate relative to the corresponding wild-type strains in independent-sample $t$ tests $(P<0.05)$. E and $\mathbf{F}$, Bacterial numbers in leaves at 0 and 3 dpi. In B, D, E and F, columns and vertical bars indicate the means and standard errors of three biological replicates. Asterisks indicate relative to the corresponding wild-type strains in independent-sample $t$ tests $(P<0.05)$. 
The functions of catalases differ among organisms. katA is the major catalase gene induced in $P$. aeruginosa in response to $\mathrm{H}_{2} \mathrm{O}_{2}$ (Heo et al. 2010). Catalase KatE performs compensatory roles in $\mathrm{H}_{2} \mathrm{O}_{2}$ metabolism in Brucella abortus (Steele et al. 2010). Catalases CatA and CatB are active at different stages of the Aspergillus nidulans life cycle (Kawasaki et al. 1997). In our study, we found that $c a t B$ was more important than katE in $X$. oryzae pvs. oryzae and oryzicola. Deletion of $c a t B$ reduced the growth rate, while double deletion of $c a t B$ and $k a t E$ completely inhibited the growth of $X$. oryzae pvs. oryzae and oryzicola in MMX medium (Fig. 5). These results suggested that catalase activity influences the growth of $X$. oryzae pvs. oryzae and oryzicola only under adverse conditions. Therefore, we used NB medium in subsequent experiments to minimize the effects of the mutations on growth.

Knockout of $c a t B$ caused transcript levels of $k a t E$ to be upregulated in $X$. oryzae pvs. oryzae and oryzicola. Relative to the wild-type strains, however, $X$. oryzae pv. oryzae and $X$. oryzae pv. oryzicola mutants $\Delta Z / k a t E$ and $\Delta R / k a t E$, respectively, showed no significant change in catalase activity or sensitivity to $\mathrm{H}_{2} \mathrm{O}_{2}$ or PCA, suggesting that, in these bacteria, katE is not the major gene responsible for catalase activity, which is consistent with a previous finding for X. oryzae pv. oryzae strain PXO99 (Wang et al. 2013b). We also found that the double deletion mutants of $X$. oryzae pv. oryzae ZJ173 and $X$. oryzae pv. oryzicola RS105, $\Delta Z /$ catB/katE and $\Delta R /$ catB/katE, respectively, did not significantly differ in catalase activity or sensitivity to $\mathrm{H}_{2} \mathrm{O}_{2}$ or PCA compared with the mutants impaired only in $c a t B$, further confirming that $k a t E$ is not the major gene responsible for catalase activity in these bacteria. The combined results concerning the growth of mutants $\Delta Z / \mathrm{cat} B, \Delta R / \mathrm{cat} B, \Delta Z / \mathrm{cat} B / \mathrm{kat} E$, and $\Delta R / c a t B / k a t E$ in MMX medium suggest that $c a t B$ may act as a repressor of $k a t E$ and that $k a t E$ could help compensate for loss of $c a t B$ in growth; however, this remains to be determined.

In a previous study, $\mathrm{H}_{2} \mathrm{O}_{2}$ toxicity was increased in Shewanella oneidensis when kat $B$, a heme-containing catalase involved in $\mathrm{H}_{2} \mathrm{O}_{2}$ degradation, was inactivated (Wu et al. 2015). In our study, inactivation of $c a t B$ caused a $72 \%$ reduction in total catalase activity in $X$. oryzae pv. oryzae and an $83 \%$ reduction in $X$. oryzae pv. oryzicola (Fig. 6). Inactivation of cat $B$ increased the sensitivity of $X$. oryzae pvs. oryzae and oryzicola to $\mathrm{H}_{2} \mathrm{O}_{2}$ (Fig. 7) and PCA (Table 2), indicating that $c a t B$ rather than katE protects against $\mathrm{H}_{2} \mathrm{O}_{2}$ and PCA in these bacteria. These results are consistent with a previous report showing that expression of catB from Deinococcus radiodurans in $E$. coli $\mathrm{UM} 2$ restored resistance to low concentrations of $\mathrm{H}_{2} \mathrm{O}_{2}$ (Zheng et al. 2000). Complementation of mutants $\Delta Z /$ catB/katE and $\Delta R / \mathrm{catB} / \mathrm{kat} E$ with corresponding $\mathrm{cat} B$ genes from strains ZJ173 and RS105, respectively, restored the wild-type phenotypes, confirming that catB is responsible for most of the catalase activity that reduces oxidative stress in $X$. oryzae pvs. oryzae and oryzicola.

Virulence and bacterial numbers were reduced in mutants $\Delta Z /$ $c a t B$ and $\Delta R /$ cat $B$ relative to the wild-type strains, and were further reduced in $\Delta Z / \mathrm{cat} B / \mathrm{kat} E$ and $\Delta R / \mathrm{catB} / \mathrm{kat} E$ (Fig. 8). These results indicate that $c a t B$ is critical for the virulence and proliferation of $X$. oryzae pvs. oryzae and oryzicola in rice leaves. In citrus, the monofunctional catalase KatE of Xanthomonas axonopodis pv. citri is required for full virulence (Tondo et al. 2010). Virulence of $X$. oryzae pvs. oryzae and oryzicola may be partially dependent on growth because the reduced virulence of the mutants was associated with their reduced growth in rice leaves. Another key factor associated with the reduced virulence of $\Delta Z / c a t B, \Delta R / c a t B, \Delta Z /$ catB/katE, and $\Delta R /$ catB/katE could be ROS intolerance caused by the deregulation of the detoxification system. Without $c a t B$, catalase activity is likely reduced, making the mutants more susceptible to the ROS burst.

In summary, we found that $c a t B$ plays a crucial role in the pathogenicity of $X$. oryzae pvs. oryzae and oryzicola and in their ability to survive oxidative stress. The results also provide insight into how PCA affects X. oryzae pvs. oryzae and oryzicola. Finally, our results indicate that $X$. oryzae pvs. oryzae and oryzicola differ greatly in catalase activity and sensitivity to PCA and $\mathrm{H}_{2} \mathrm{O}_{2}$.

\section{ACKNOWLEDGMENTS}

This research was funded by the Special Fund for Agro-Scientific Research in the Public Interest (201303023) and the Fund for Independent Innovation of Agricultural Science and Technology in Jiangsu Province (CX(15)1054).

\section{LITERATURE CITED}

Arata, T., Hori, M., and Inoue, Y. 1961. On the phytotoxicity of streptomycin to rice plant. Ann. Phytopathol. Soc. Japan 26:78.

Chelikani, P., Fita, I., and Loewen, P. C. 2004. Diversity of structures and properties among catalases. Cell. Mol. Life Sci. 61:192-208.

Chen, H. X., Du, X. B., Zhang, H., and Li, B. X. 2012. Field efficacy of Shenqinmycin on rice sheath blight (Rhizoctonia solani). Acta Agric. Shanghai. 28:69-71.

Hassan, H. M., and Fridovich, I. 1979. Intracellular production of superoxide radical and of hydrogen peroxide by redox active compounds. Arch. Biochem. Biophys. 196:385-395.

Heo, Y. J., Chung, I. Y., Cho, W. J., Lee, B. Y., Kim, J. H., Choi, K. H., Lee, J. W., Hassett, D. J., and Cho, Y. H. 2010. The major catalase gene (katA) of Pseudomonas aeruginosa PA14 is under both positive and negative control of the global transactivator OxyR in response to hydrogen peroxide. J. Bacteriol. 192:381-390.

Hertzberger, R., Arents, J., Dekker, H. L., Pridmore, R. D., Gysler, C., Kleerebezem, M., and de Mattos, M. J. 2014. $\mathrm{H}_{2} \mathrm{O}_{2}$ production in species of the Lactobacillus acidophilus group: A central role for a novel NADHdependent flavin reductase. Appl. Environ. Microbiol. 80:2229-2239.

Huang, H., Sun, L., Bi, K., Zhong, G., and Hu, M. 2016. The effect of phenazine-1-carboxylic acid on the morphological, physiological, and molecular characteristics of Phellinus noxius. Molecules 21:613. doi: 10.3390/molecules21050613

Kawasaki, L., Wysong, D., Diamond, R., and Aguirre, J. 1997. Two divergent catalase genes are differentially regulated during Aspergillus nidulans development and oxidative stress. J. Bacteriol. 179:3284-3292.

Klotz, M. G., Klassen, G. R., and Loewen, P. C. 1997. Phylogenetic relationships among prokaryotic and eukaryotic catalases. Mol. Biol. Evol. 14:951-958.

Kumar, S., Nei, M., Dudley, J., and Tamura, K. 2008. MEGA: A biologistcentric software for evolutionary analysis of DNA and protein sequences. Brief. Bioinf. 9:299-306.

Lan, L., Murray, T. S., Kazmierczak, B. I., and He, C. 2010. Pseudomonas aeruginosa OspR is an oxidative stress sensing regulator that affects pigment production, antibiotic resistance and dissemination during infection. Mol. Microbiol. 75:76-91

Laursen, J. B., and Nielsen, J. 2004. Phenazine natural products: Biosynthesis, synthetic analogues, and biological activity. Chem. Rev. 104:1663-1686.

Look, D. C., Stoll, L. L., Romig, S. A., Humlicek, A., Britigan, B. E., and Denning, G. M. 2005. Pyocyanin and its precursor phenazine-1-carboxylic acid increase IL-8 and intercellular adhesion molecule-1 expression in human airway epithelial cells by oxidant-dependent mechanisms. J. Immunol. 175:4017-4023.

Lu, X. W., Xu, H., Sun, B., Zhu, Z. S., Zheng, D. H., and Li, X. L. 2013. Enhanced neuroprotective effects of resveratrol delivered by nanoparticles on hydrogen peroxide-induced oxidative stress in rat cortical cell culture. Mol. Pharm. 10:2045-2053.

Mavrodi, D. V., Blankenfeldt, W., and Thomashow, L. S. 2006. Phenazine compounds in fluorescent Pseudomonas spp. biosynthesis and regulation. Annu. Rev. Phytopathol. 44:417-445.

Ou, S. H. 1985. Rice Diseases. Commonwealth Mycological Institute, Kew, Surrey, UK.

Pridmore, R. D., Pittet, A. C., Praplan, F., and Cavadini, C. 2008. Hydrogen peroxide production by Lactobacillus johnsonii NCC 533 and its role in anti-Salmonella activity. FEMS Microbiol. Lett. 283:210-215.

Qian, G., Liu, C., Wu, G., Yin, F., Zhao, Y., Zhou, Y., Zhang, Y., Song, Z., Fan, J., Hu, B., and Liu, F. 2013. AsnB, regulated by diffusible signal factor and global regulator Clp, is involved in aspartate metabolism, resistance to oxidative stress and virulence in Xanthomonas oryzae pv. oryzicola. Mol. Plant Pathol. 14:145-157.

Reczek, C. R., and Chandel, N. S. 2015. ROS-dependent signal transduction. Curr. Opin. Cell Biol. 33:8-13.

Riley, P. A. 1994. Free radicals in biology: Oxidative stress and the effects of ionizing radiation. Int. J. Radiat. Biol. 65:27-33.

Schouten, A., Tenberge, K. B., Vermeer, J., Stewart, J., Wagemakers, L., Williamson, B., and van Kan, J. A. 2002. Functional analysis of an extracellular catalase of Botrytis cinerea. Mol. Plant Pathol. 3:227-238. 
Steele, K. H., Baumgartner, J. E., Valderas, M. W., and Roop, R. M., II. 2010. Comparative study of the roles of AhpC and KatE as respiratory antioxidants in Brucella abortus 2308. J. Bacteriol. 192:4912-4922.

Switala, J., Triggs-Raine, B. L., and Loewen, P. C. 1990. Homology among bacterial catalase genes. Can. J. Microbiol. 36:728-731.

Toledano, M. B., Planson, A. G., and Delaunay-Moisan, A. 2010. Reining in $\mathrm{H}_{2} \mathrm{O}_{2}$ for safe signaling. Cell 140:454-456.

Tondo, M. L., Petrocelli, S., Ottado, J., and Orellano, E. G. 2010. The monofunctional catalase KatE of Xanthomonas axonopodis pv. citri is required for full virulence in citrus plants. PLoS One 5:e10803.

Wang, L., Duan, Q., Wang, T., Ahmed, M., Zhang, N., Li, Y., Li, L., and Yao, X. 2015. Mitochondrial respiratory chain inhibitors involved in ROS production induced by acute high concentrations of iodide and the effects of sod as a protective factor. Oxid. Med. Cell. Longev. 2015:Article ID 217670. doi:10.1155/2015/217670

Wang, N., Wu, M. S., Tian, F., Chen, H. M., and He, C. Y. 2013a. Effects of gene deletion of katExoo encoding putative catalase on resistance to hydrogen peroxide and pathogenicity of Xanthomonas oryzae pv. oryzae. Acta Pharmacol. Sin. 43:615-621.

Wang, Z. L., Zhang, L. B., Ying, S. H., and Feng, M. G. 2013b. Catalases play differentiated roles in the adaptation of a fungal entomopathogen to environmental stresses. Environ. Microbiol. 15:409-418.

Wu, G., Wan, F., Fu, H., Li, N., and Gao, H. 2015. A matter of timing: Contrasting effects of hydrogen sulfide on oxidative stress response in Shewanella oneidensis. J. Bacteriol. 197:3563-3572.

Xu, S., Pan, X. Y., Luo, J., Wu, J., Zhou, Z. H., Liang, X. Y., He, Y. W., and Zhou, M. G. 2015. Effects of phenazine-1-carboxylic acid on the biology of the plant-pathogenic bacterium Xanthomonas oryzae pv. oryzae. Pestic. Biochem. Physiol. 117:39-46.
Yang, B., and Bogdanove, A. 2013. Inoculation and virulence assay for bacterial blight and bacterial leaf streak of rice. Methods Mol. Biol. 956: 249-55.

Ye, L., Zhang, H., Xu, H., Zou, Q., Cheng, C., Dong, D., Xu, Y., and Li, R. 2010. Phenazine-1-carboxylic acid derivatives: Design, synthesis and biological evaluation against Rhizoctonia solani Kuhn. Bioorg. Med. Chem. Lett. 20:7369-7371.

Yoneyama, K., Shimeno, K., Taguchi, R., and Misatoa, T. 1969. Studies on the screening methods of the chemicals for bacterial leaf blight of rice plant. Agric. Biol. Chem. 43:851-856.

Yu, X. Y., Liang, X. Y., Liu, K. X., Dong, W. X., Wang, J. X., and Zhou, M. G. 2015. The thiG gene is required for full virulence of Xanthomonas oryzae pv. oryzae by preventing cell aggregation. PLoS One 10:e0134237.

Zhang, S., Chen, H. X., Du, X. B., Zhang, Q., and Xu, Y. Q. 2015. The action mode and control efficacy of Shenqinmycin (phenazino-1-carboxylic acid) combined with paddy common pesticides against rice sheath blight (Rhizoctonia solani). Acta Agric. Shanghai. 31:1-4.

Zheng, H., Lu, X., Xing, R. Y., Lu, P., and Yao, Q. Z. 2000. Deinococcus radiodurans CatB Gene Cloning and Expression in Escherichia coli. Acta Biochim. Biophys. Sin. (Shanghai) 32:417-420.

Zhou, L., Jiang, H. X., Sun, S., Yang, D. D., Jin, K. M., Zhang, W., and He, Y. W. 2016. Biotechnological potential of a rhizosphere Pseudomonas aeruginosa strain producing phenazine-1-carboxylic acid and phenazine-1-carboxamide. World J. Microbiol. Biotechnol. 32:50. doi:10.1007/s11274-015-1987-y

Zhou, L. H., Han, Y., Yang, J., Li, M., and Ji, G. H. 2014. The sensitive baseline of Xanthomonas oryzae pv. oryzicola in southwest China to pheazino-1-carboxylic acid and zinc thiazole. J. Anhui Univ. 38:97-102.

Zhou, Z., and Zhang, X. 2016. Control effect of phenazino-1-carboxylic acid against rice blast in Guangdong. Pestic. Sci. Admin. 37:59-62. 